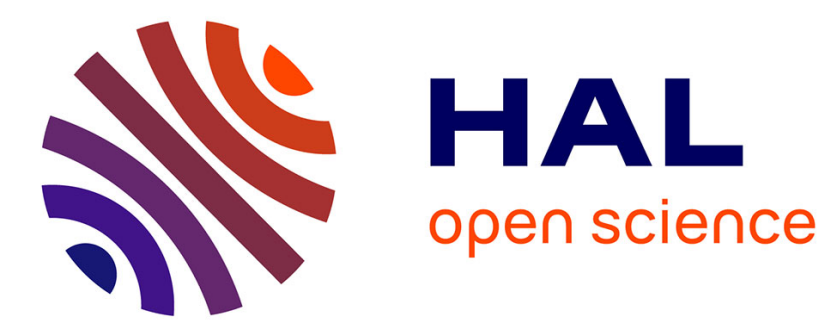

\title{
Stability Analysis of a Flexible Bladed-rotor
}

Nicolas Lesaffre, Jean-Jacques Sinou, Fabrice Thouverez

\section{To cite this version:}

Nicolas Lesaffre, Jean-Jacques Sinou, Fabrice Thouverez. Stability Analysis of a Flexible Bladed-rotor.

Key Engineering Materials, 2005, 292-294, pp.409-416. hal-00322910

\section{HAL Id: hal-00322910 https://hal.science/hal-00322910}

Submitted on 5 Feb 2013

HAL is a multi-disciplinary open access archive for the deposit and dissemination of scientific research documents, whether they are published or not. The documents may come from teaching and research institutions in France or abroad, or from public or private research centers.
L'archive ouverte pluridisciplinaire HAL, est destinée au dépôt et à la diffusion de documents scientifiques de niveau recherche, publiés ou non, émanant des établissements d'enseignement et de recherche français ou étrangers, des laboratoires publics ou privés. 


\title{
Stability analysis of a flexible bladed-rotor
}

\author{
N. Lesaffre, J-J. Sinou and F. Thouverez \\ Ecole Centrale de Lyon \\ Laboratoire de Tribologie et Dynamique des Systèmes, UMR CNRS 5513 \\ Equipe Dynamique des Systèmes et des Structures \\ 36 avenue Guy de Collongue 69134 Ecully Cedex, FRANCE \\ tel: + 33 (0)4 72186479 fax: + 33 (0)4 72189144 \\ e-mail: nicolas.lesaffre@ec-lyon.fr \\ e-mail: jean-jacques.sinou@ec-lyon.fr \\ e-mail: fabrice.thouverez@ec-lyon.fr
}

Keywords: Rotordynamics, instability prediction, flexible bladed-rotor, parametric studies.

\begin{abstract}
In any high-performance turbo-machinery, instability prediction and damage are commonly occurring problems. The aim of this paper is to present stability analysis of a fully-bladed flexible rotor. The flexural vibrations of the blades as well as those of the shaft are considered; the energetic approach used includes the effect of the rotational inertia.

Then stability detection, bringing loci veering phenomena and coalescence, in case of asymmetric rotor, to the fore, is made in order to determine a parametric domain where turbomachinery cannot encounter damages. Moreover, extensive parametric studies including for instance the length and the stagger angle of the blades are presented in order to obtain robust criterion for stable and unstable areas prediction.

Finally, the rotor/stator contact is introduced and the effect of the radial load acting on the blades when rubbing against a carter is considered.
\end{abstract}

\section{Introduction}

The basic objective of turbo-machinery designers is to increase the efficiency of their machine. The efficiencies of both turbo-generators and jet engines depend strongly on the clearance between the rotating and the stationary parts [1,2]: the wider the clearance, the less efficient the machine. Hence it is desirable to reduce the clearance by as much as possible. It cannot be reduced below a certain minimum level due to uncertainties in the dynamics, fluid dynamics [3,4], thermal loads [5], the machining tolerances and material properties [6,7]. The more accurate these parameters are known, the smaller the clearance can be made. However, reduced clearances increase the possibility of violent contacts between rotor and stator and under certain operating conditions, including the dynamic properties of the rotor and the stator and the speed of rotation, the contacts may continue and drive the rotor-stator system unstable $[8,9,10]$.

A common interest of the rotating-machinery industry is to better understand the dynamic behaviour of rotating structures and in particular that of flexible bladed-rotor whose dynamic behaviour differs from those usually studied in rotor-dynamics. Thus, the instability of 
propellers due to the interaction between the dynamics of the blades and that of the engine suspension is a well-known phenomenon [11]. This kind of instability may also occur in bladed-rotor, like those present in turbo-machinery [12].

The study of such structure is quite complex and must be performed using numerical models. However, to obtain a closed form solution suitable for a stability analysis, it is possible to resort to simplified models [13,14 and 15]. In this paper, a model of fully-bladed flexible rotor constructed by using an energetic approach is firstly presented. Then, in a second part, stability analysis and parametric studies are investigated in order to detect the stable and unstable regions of this structure in case of dissymmetries. Finally, the contact between the blade tips and a stator is introduced.

\section{Model formulation}

The rotor considered in this study is shown in Fig.1(a). It has been developed on an energetic approach based on the same kind of approximation as the one described by Sinha [13]. It consists of a shaft modelled by an Euler-Bernoulli beam, connected to a rigid disk modelled by a punctual mass with rotational inertia. Several Euler-Bernoulli beams are clamped in the disk and model the blades. The shaft is set on bearings at multiple locations.

Two degrees of freedom are considered for the shaft: two orthogonal translations $u(z, t)$ and $v(z, t)$ in the disk's plan (see Fig. 1(b)), and one degree of freedom for each blade defining its deflection $\eta(s, t)$.

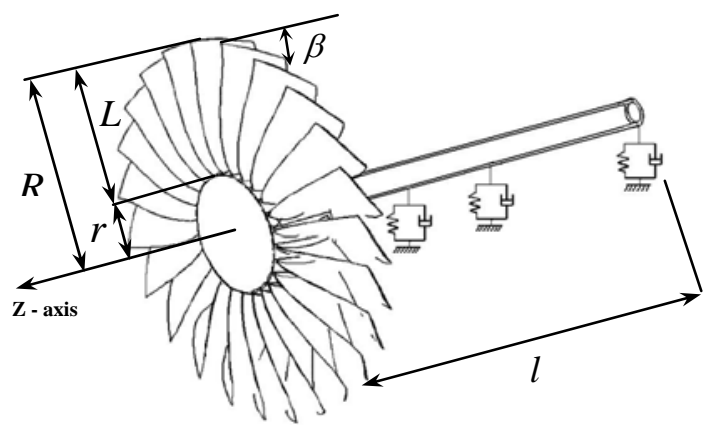

(a)

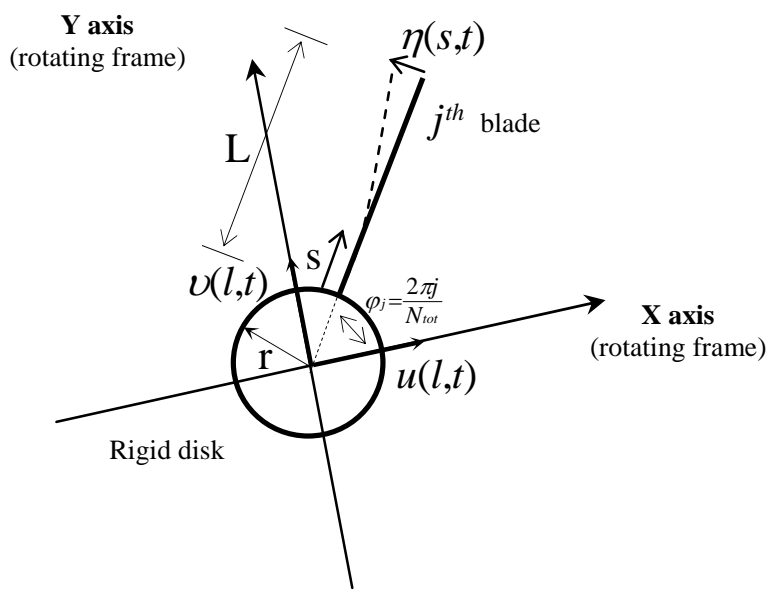

(b)

Figure 1 (a) Model of flexible bladed-rotor (Sinha [13]) (b) Front view of the bladed-disk

A Rayleigh-Ritz approximation is used to express the degrees of freedom of these different parts. Thus, they are expressed by a sum of shape functions level-headed by time-dependant coefficients.

$$
\begin{gathered}
u(z, t)=U_{o}(t)+\sum_{m=1}^{m_{\text {of }}} U_{m}(t) W_{m}(z) \\
v(z, t)=V_{o}(t)+\sum_{m=1}^{m_{\text {ov }}} V_{m}(t) W_{m}(z) \\
\eta(s, t)=\sum_{n=1}^{n_{\text {oft }}}\left(X_{n}(t)\right)_{j}\left(Y_{n}(s)\right)_{j}
\end{gathered}
$$

where $z$ is the abscissa of the shaft and $s$, the abscissa along the blade. In these expressions, $U_{o}(t)$ and $V_{o}(t)$ are rigid-body translations of the shaft, $m_{\text {tot }}$ and $n_{\text {tot }}$, the number of modes considered to express its motion and the flexion of the $j^{\text {th }}$ blade respectively. In this 
Rayleigh-Ritz approach, the shape functions have only to verify the cinematic conditions of the problem so, the shape functions of the blades must verify $Y_{n}(0)=0$ and $Y_{n}^{\prime}(0)=0$, where prime denotes differentiation versus space coordinates, because they are clamped in the rigid disk. Thus, the chosen expression for the shape function of the blade deflection is: $Y_{n}(s)=a_{1 n} s+\sin \left(\beta_{n} s\right)$ with $\beta_{n}=(2 n-1) \pi /(2 L)$ and $a_{1 n}=-\beta_{n}$. Concerning the shaft, since its is supported by bearings, its shape function has no cinematic conditions to verify and its chosen expression is: $W_{m}(z)=1-\cos \left(\alpha_{m} z\right)$ with $\alpha_{m}=(2 m-1) \pi /(2 l)$.

An energetic method is used to develop this model thus, potentials have to be defined for the shaft and for the blades as well. The model has been fully developed in the rotating frame in order to avoid having time-dependant terms, resulting from the periodicity of the rotating structure, in the analytical formulation. Thus, the kinetic energy Tblade of the $j^{\text {th }}$ blade, located at an angle $\varphi_{j}=\frac{2 \pi j}{N_{\text {tot }}}$ in this frame, as indicated in Fig. 1(b) and where $N_{\text {tot }}$ is the total number of blades, can be fully expressed by the following relation:

$$
T_{\text {blade }}=\int_{0}^{L} \frac{1}{2} \rho_{b} S_{b} \vec{V}_{S / R_{0}}^{2}(G) d s+\int_{0}^{L} \frac{1}{2} \vec{\Omega}_{S / R_{0}}^{T} \mathbf{I} \vec{\Omega}_{S / R_{0}} d s
$$

where $\rho_{b}$ and $S_{b}$ are the density and the area respectively of a blade cross section and $\vec{V}_{S / R 0}(G), \vec{\Omega}_{S / R 0}$ and I are the speed and the rotation of the center of mass of a blade cross section in relation to the fixed frame and its inertia matrix, defined in its inertial frame.

A potential energy $v_{\text {intblade }}$ associated with the elastic deformation of the blade, a function of dissipation $F_{\text {dblade }}$ associated with the internal damping of the $j^{\text {th }}$ blade and a pre-stress potential $\quad v_{g_{\text {blade }}}=\frac{1}{2} \int_{0}^{L} \rho_{b} S_{b} \Omega^{2}\left[\frac{R^{2}-(s+r)^{2}}{2}\right] \eta^{\prime 2}(s, t) d s$ taking into account the effect of the rotational inertia are formulated.

In the same way, a kinetic energy $T_{\text {shaft }}$, a potential energy $v_{\text {intshat }}$ associated with the elastic deformation of the shaft, a function of dissipation $F_{d \text { shaft }}$ associated with the internal damping of the shaft as well as a potential vbearings and a function of dissipation $F_{\text {dberings }}$ associated with the bearing are defined.

Then, Lagrange's equations are used to obtain the system of equations of the dynamic behaviour of the full flexible bladed-rotor. This system of equations can be set under the following form:

$$
\mathbf{M} \ddot{\mathbf{X}}+\tilde{\mathbf{C}} \dot{\mathbf{X}}+\tilde{\mathbf{K}} \mathbf{X}=\mathbf{0}
$$

where $\mathbf{M}, \tilde{\mathbf{C}}$ and $\tilde{\mathbf{K}}$ are the mass matrix, the generalised damping matrix and the generalised stiffness matrix respectively. $\mathbf{x}$ which defines the generalised degree of freedom vector of the system contains $2 m_{\text {tot }}+2+n_{\text {tot }} N_{\text {tot }}$ elements and has the following expression:

$$
\mathbf{X}=\left[\begin{array}{lllllllllllllllll}
U_{0} & V_{0} & U_{1} & V_{1} & \ldots & U_{m_{\text {ot }}} & V_{m_{\text {ot }}} & X_{11} & X_{21} & \ldots & X_{n_{\text {ot }} 1} & \ldots & \ldots & X_{1 N_{\text {tot }}} & \ldots & X_{n_{\text {tot }} N_{\text {tot }}}
\end{array}\right]^{T}
$$

\section{Stability analysis}

As explained previously, one of the most important objectives for turbo-machinery designers is to define dangerous operating speed ranges and the associated stable and unstable regions of bladed-rotor vibrations. The stability of the flexible bladed rotor is investigated by determining the solution $\lambda$ of the characteristic equation $\operatorname{det}\left(\lambda^{2} \mathbf{M}+\lambda \tilde{\mathbf{C}}+\tilde{\mathbf{K}}\right)=0 . \quad \lambda$ can be expressed as $\lambda=a+i b$. The flexible bladed-rotor becomes unstable if any of the real part $a$ is positive. 
In this following study, we consider a shaft supported by three diagonal bearings located at its free, and at $300 \mathrm{~cm}$ and at $325 \mathrm{~cm}$ and whose radial stiffness and radial viscous damping coefficients are $k_{\text {bearing }}=2 \cdot 10^{7} \mathrm{~N} \cdot \mathrm{m}^{-1}$ and $D_{\text {bearaing }}=2 \cdot 10^{3} \mathrm{~N}$.s. $\mathrm{m}^{-1}$.

Fig. 2(a) illustrates the evolution of the eigen frequencies of a flexible twenty eight-bladedrotor of one meter in length, plotted in a Campbell diagram. Fig. 2(b) shows the evolution of the eigenvalues in the complex plane. The evolutions of the shaft's eigen frequencies, shown on Fig.2(a), are mainly due to the gyroscopic effects. The evolution of the blades' eigen frequencies (starting at $31 \mathrm{~Hz}$ ) i.e. their stiffening, is due to the centrifugal effects included in the pre stress potential $v_{\text {gblade }}$. Two loci veering phenomena can be seen and are located by the points A and B on Fig. 2. When two eigenvalue loci approach each other, they either cross or do not cross; often in the latter case, even though the loci nearly intersect, in fact they do not but rather veer away from each other with high local curvature. During these phenomena, mode shapes and sense of rotation are switched between both eigenvalue that veer away.

The system is perfectly stable as shown on Fig. 2(b). However, in the particular case of a twobladed rotor, in addition to loci veering phenomena, instabilities can be observed as illustrated in Fig.3. In this case, two kinds of instabilities are observed. They both result from an inertial dissymmetry of the system. The first and more common one is noted by (1) and occurs at the first critical speed (intersection with the abscissa axis). The second one, indicated by 2b, 2c and $2 \mathrm{~d}$, consists in mode couplings i.e. two separated mode shapes at a speed rotation become two mode shapes having the same eigen frequency but one of them being stable and the other being unstable with its amplitude increasing in the time. The points indicated by X1 and X2 do not show instabilities but since the observed phenomenon is due to dissymmetry, one can think, essentially by looking Fig.3(b), that the length of the blades will influence mode couplings and for sufficient length may drive the two-bladed rotor instable at these configurations.

Fig.4(a) shows a stability map for a two-bladed rotor function of its rotation speed and of its blade length and Fig.4(b) shows the instable frequencies associated. These two pictures confirm the two kinds of instabilities, the one noted (1) corresponding to $0 \mathrm{~Hz}$ and the one noted 2a, 2b, 2c and 2d corresponding to mode couplings. Fig.4(a) shows that up to $15 \mathrm{~cm}$, the dissymmetry of the rotor is sufficiently light to leave the system stable but above this blade length, the rotor may experience several speed ranges where it is unstable. Only the instable frequencies different from $0 \mathrm{~Hz}$ and corresponding to mode couplings can be seen on Fig.4(b), underlying the two kinds of instabilities. Thus, the configuration noted X1 on Fig.3 can be an instable one if the blade length is up to $1.1 \mathrm{~m}$ and corresponds to the area noted 2a. It is the same thing for the points noted X2 on Fig.3 which correspond to the area (1) just before $8000 \mathrm{tr} / \mathrm{min}$ for blades longer than $1.1 \mathrm{~m}$.

As it has been said earlier, these instabilities are mainly due to dissymmetry of the system but, the flexibility of the blades can influence these phenomena. Fig.5(a) and (b) show the stability map and the instable frequencies' evolution respectively in the case of a two-rigid-bladed rotor. 


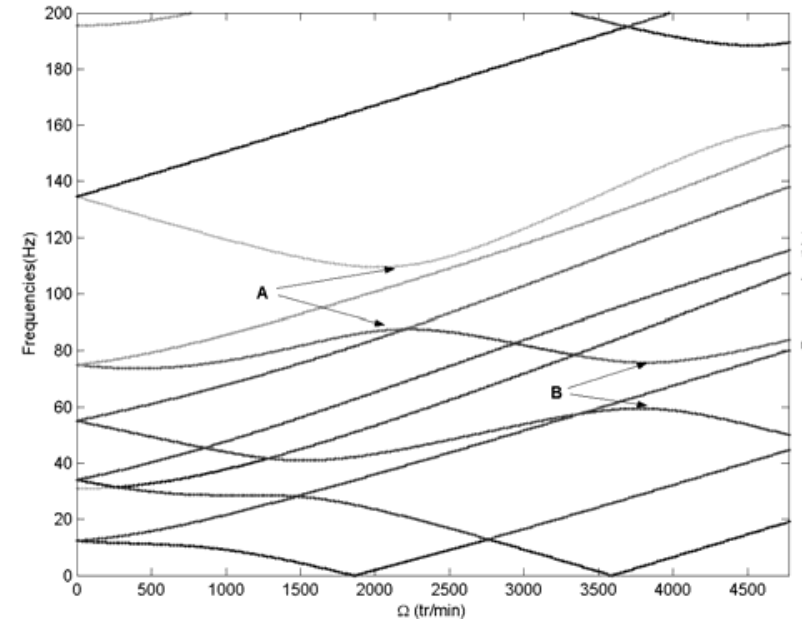

(a)

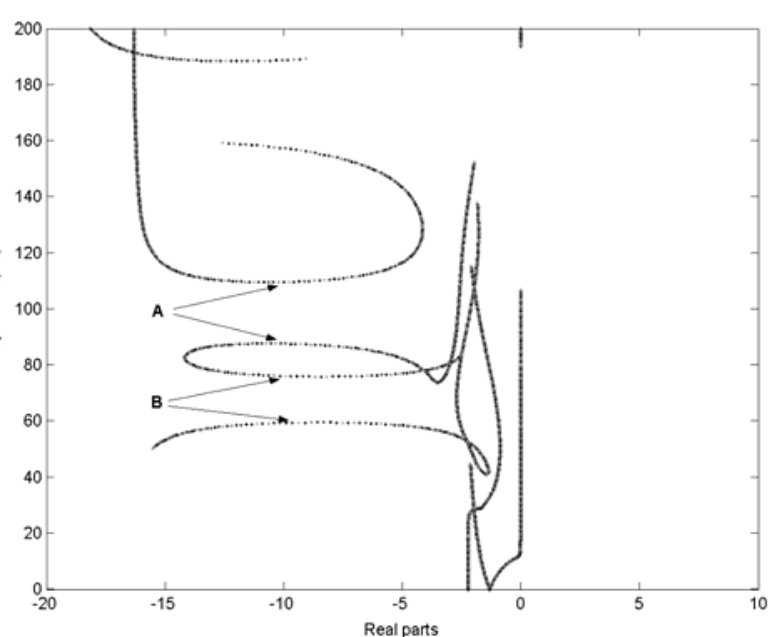

(b)

Figure 2 (a) Campbell diagram (b) Complex plane diagram for a twenty eight-bladed-rotor

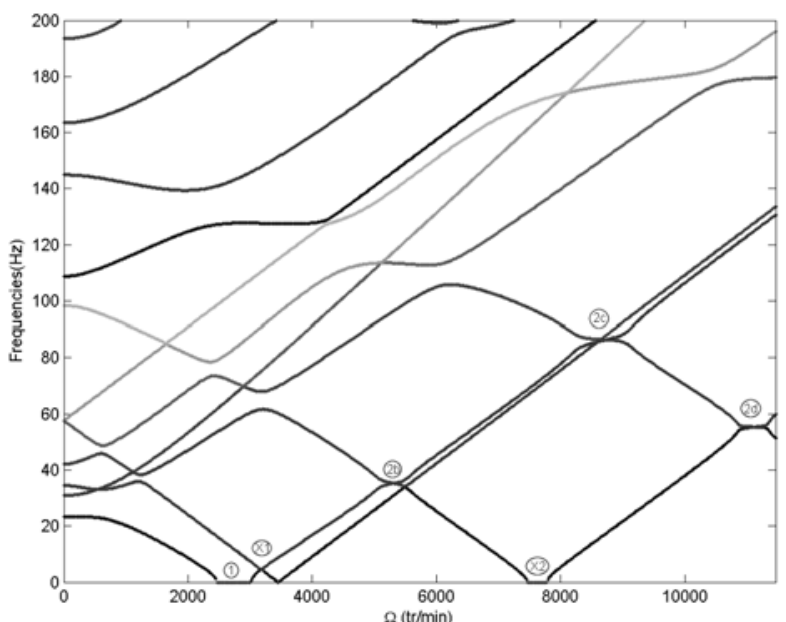

(a)

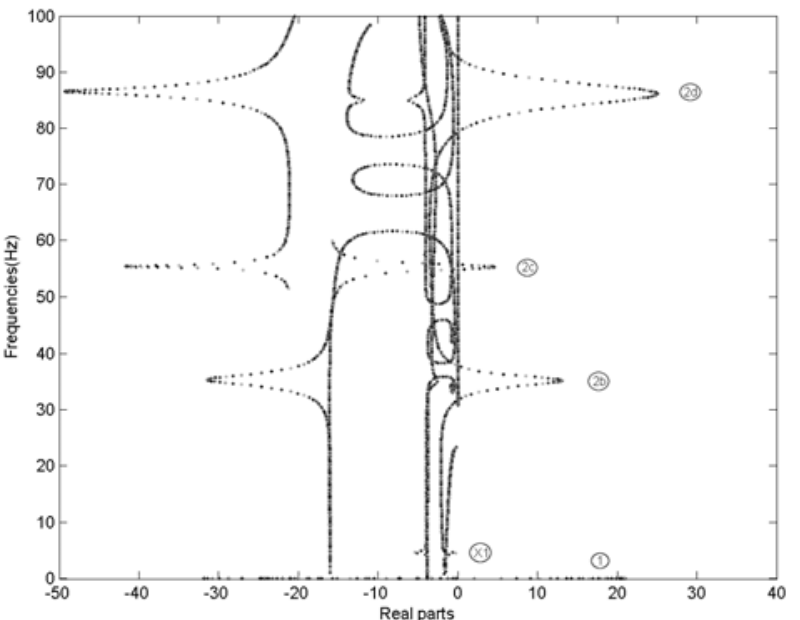

(b)

Figure 3 (a) Campbell diagram (b) Complex plane diagram for a two-bladed-rotor

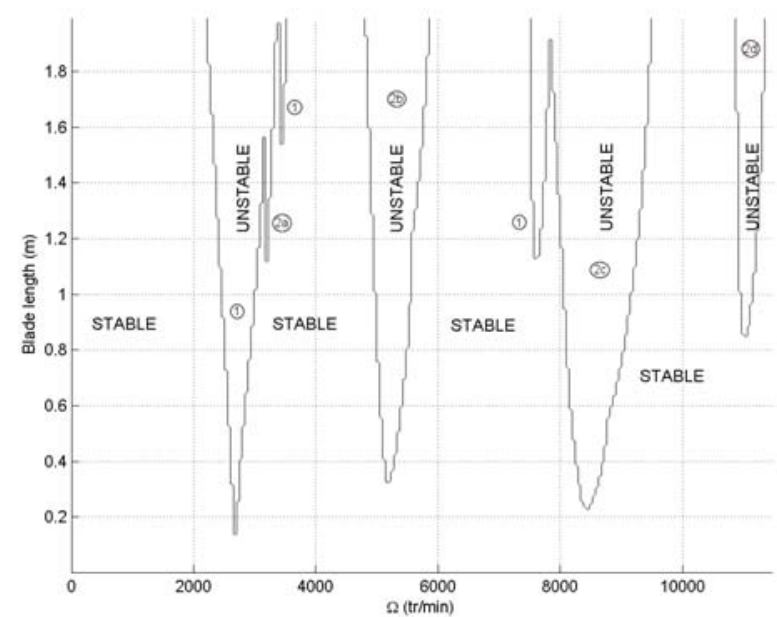

(a)

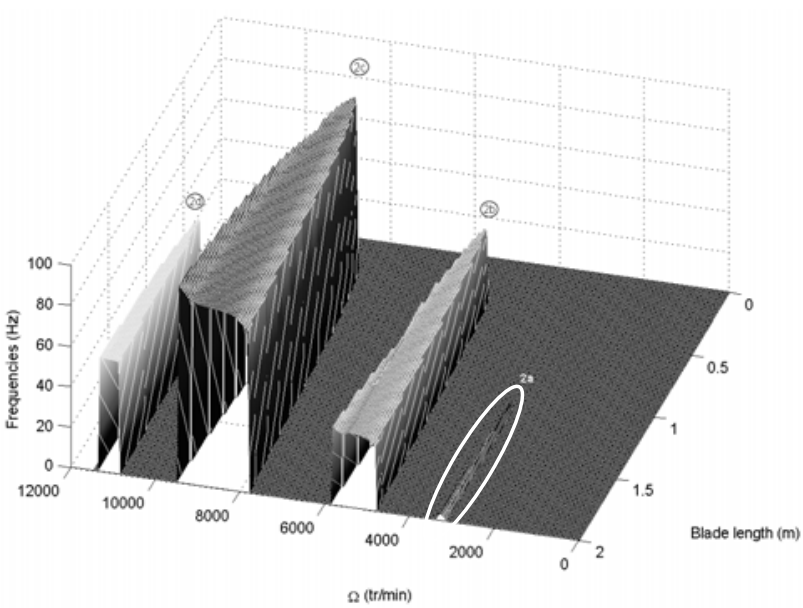

(b)

Figure 4 (a) Stability map (b) instable frequencies of a two-bladed rotor function of its blade length and its rotation speed 


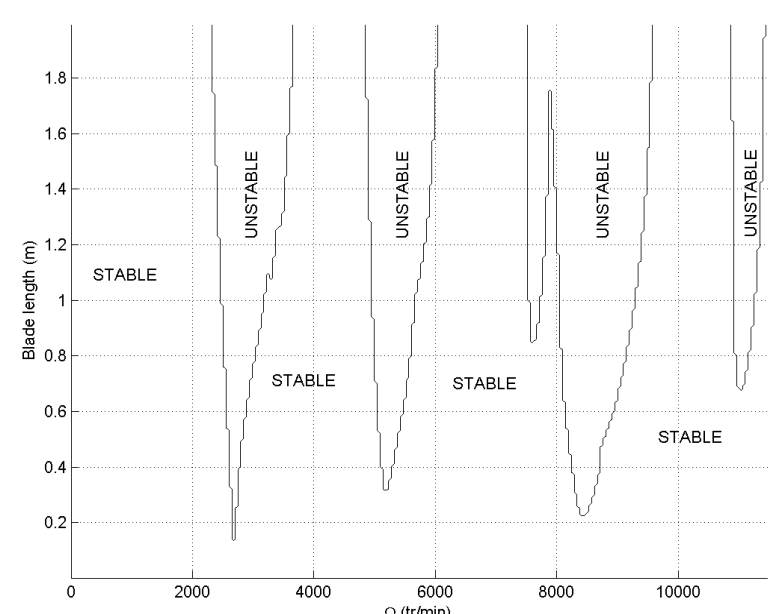

(a)

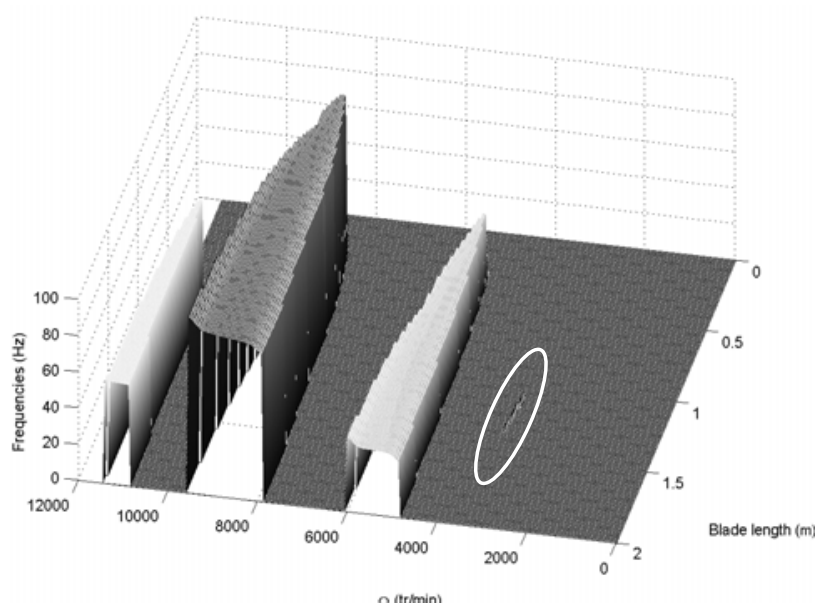

(b)

Figure 5 (a) Stability map and (b) instable frequencies of a two-rigid-bladed rotor function of its blade length and its rotation speed

The differences between this case and the latter concerns mainly the first instability range. As a matter of fact, the instable frequencies corresponding to mode couplings between 2000 $\mathrm{tr} / \mathrm{min}$ and $4000 \mathrm{tr} / \mathrm{min}$ are lower than in the flexible case and the blade length range concerned is shorter (see Fig.5(b), in white round). Thus, in the case of a two-rigid-bladed rotor, the mass and inertia added by the two blades can, between $2000 \mathrm{tr} / \mathrm{min}$ and $4000 \mathrm{tr} / \mathrm{min}$, lead to low frequency modes couplings between the horizontal and the vertical mode shape of the rotor, if its blade length is between $1.1 \mathrm{~m}$ and $1.5 \mathrm{~m}$. In the case of flexible blades, if their eigen frequencies are close to those of the shaft (as in the latter example), mode couplings can occur in this same speed range from a blade length of $1.1 \mathrm{~m}$ and concern mixed mode shapes. Another parameter, the stagger angle (see Fig.6) can influence the occurrence of instabilities. All the case studied so far have been made with $\beta=60^{\circ}$. Fig.7(a) and Fig.7(b) show the stability map and the instable frequencies' evolution respectively function of the stagger angle of a two-flexible-bladed rotor of one meter in length. The two kinds of instabilities can also be seen here. It appears that the higher the stagger angle is, the shorter the instable speed ranges are, as it could be though intuitively. However, instable speed ranges can appear or disappear function of this stagger angle, showing the importance of this parameter.

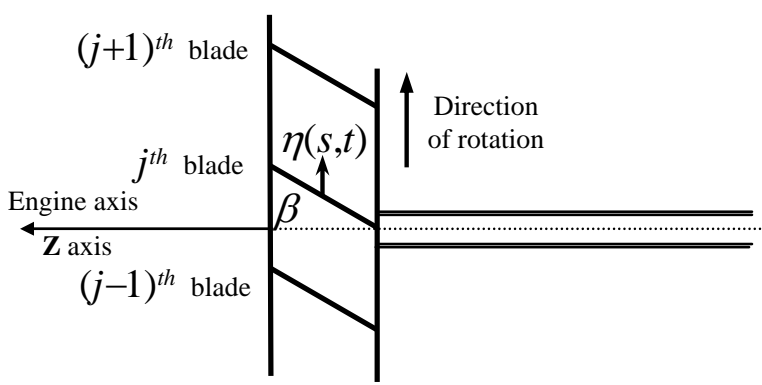

Figure 6 Up view of the bladed disk

Stagger angle $\beta$ of the blades 


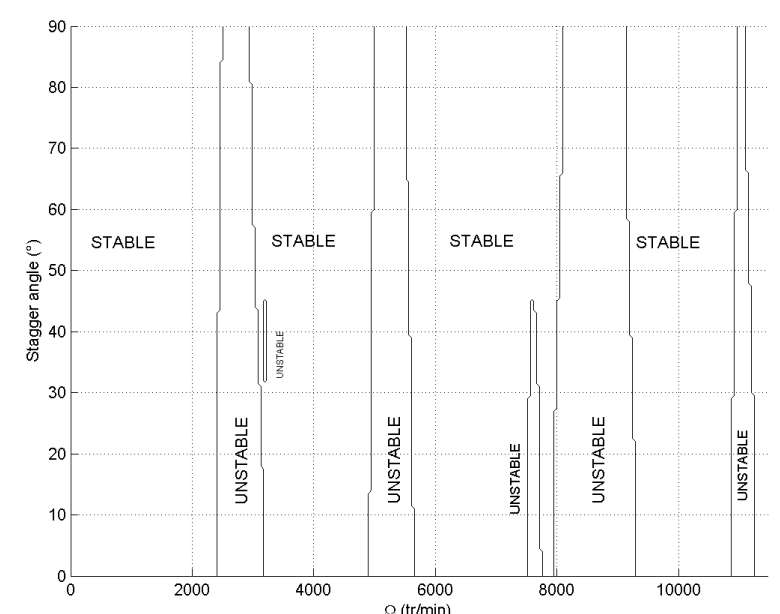

(a)

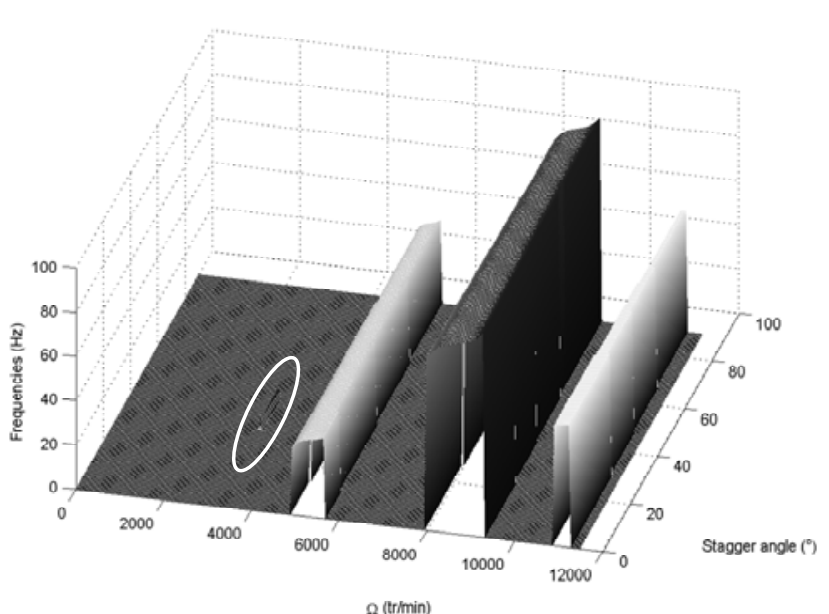

(b)

Figure 7 (a) Stability map (b) instable frequencies of a two-flexible-bladed rotor function of its stagger angle and its rotation speed

Finally, tip-blade/carter contact can be introduced. Effectively, higher energy-efficiency of the engine is achieved by reducing the tip clearance between the rotor and the stator components, but as the clearance is reduced, the probability of rub taking place during small changes in the operating conditions also increases. The contact between the blade-tips of a six-flexiblebladed rotor and a rigid stator has been modelled through a radial penalty stiffness. Thus, a potential associated to this stiffness is defined according to the energetic method and the effect of radial load on the dynamic behaviour of the rotor is investigated. In the rotating frame, this non linear problem is a static one. However, the radial displacement of the shaft at its connexion with the bladed disk has been calculated through a finite difference method and is plotted on Fig. 8(a). Fig. 8(b) shows the deformed static shape associated (where all the displacements have been multiplied by a factor in order to see the behaviour of the system) for a clearance between the blade tips and the stationary part of $100 \mu \mathrm{m}$, an unbalance mass of $100 \mathrm{g.cm}$ and a speed rotation of $5730 \mathrm{tr} / \mathrm{min}$. In this configuration, the unbalance being located at $45^{\circ}$ in the rotating frame, the rotor has two blades in steady state contact with the stator (see Fig. 8(b)).

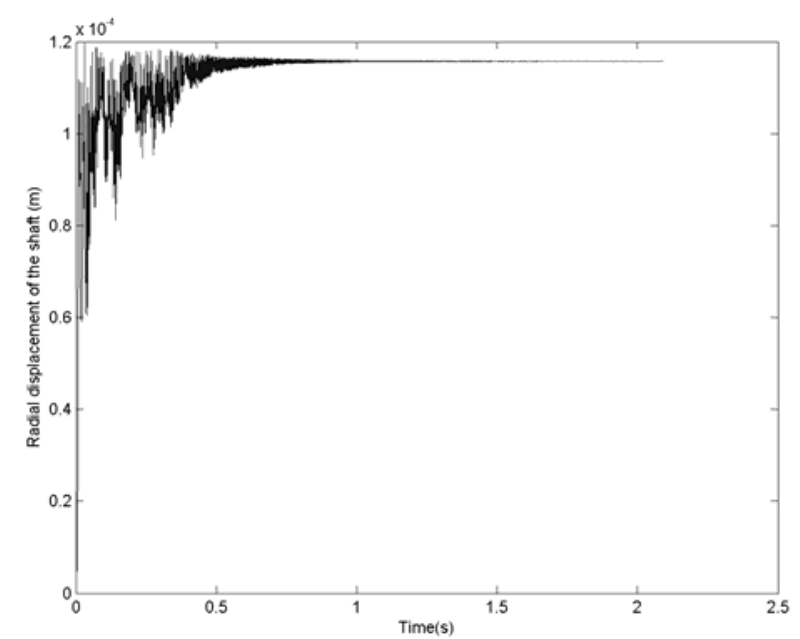

(a)

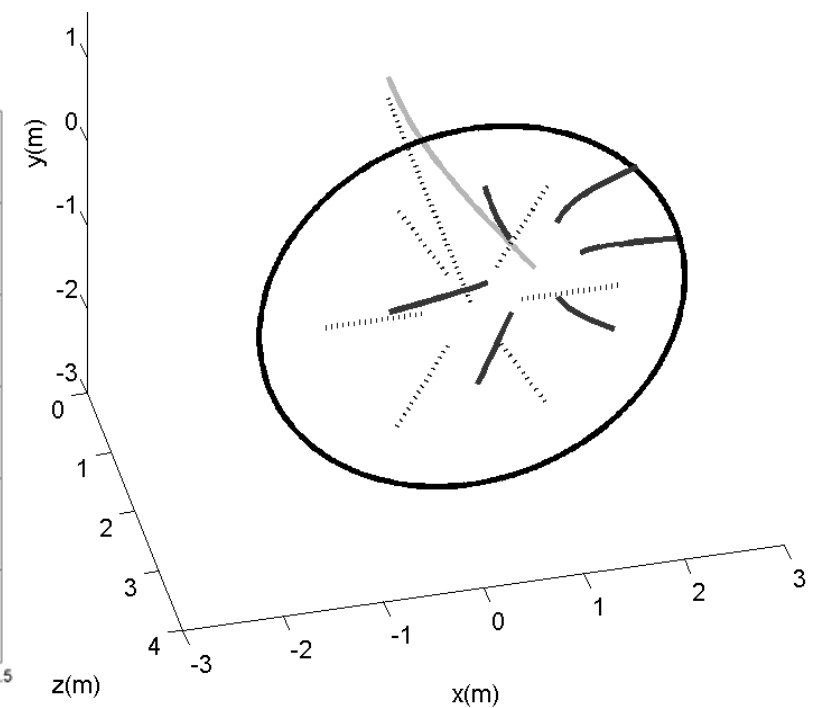

(b)

Figure 8 (a) Dynamic behaviour (b) deformed shape of a six-flexible bladed rotor in contact with a stator in the rotating frame 


\section{Conclusion}

A flexible fully bladed-rotor has been modelled in the rotating frame using an energetic approach. Then, loci veering phenomena have been brought to the fore and its stability has been investigated. It has been shown that without rotating damping, the system may experience instabilities if it is strongly dissymmetric, typically in the case of a two-bladed rotor. In this case, zero hertz instable speed ranges have been detected at the first critical speed as well as mode couplings at frequencies different from zero hertz whether the blades are flexible or not. The influence of the stagger angle of the blades in the occurrences of instabilities has also been underlined.

It has been shown that this model of flexible bladed-rotor is sufficiently simple and complete from a phenomenological point of view to be used to study easily the contact between blade tips and stationary parts in the rotating frame

\section{References}

[1] D. Childs, 1993. Turbomachinery Rotordynamics: phenomena, modelling and analysis. John Wiley \& Sons, Inc.

[2] F. F. Ehrich, 1992. Handbook of rotordynamics. Macgraw-Hill.

[3] F. F. Ehrich, 1993. Rotor Whirl Forces Induced by the Tip Clearance Effect in Axial Flow Compressors. Journal of Vibration and Acoustics, vol. 115, pp.509-515.

[4] F. Assis Rodrigues, F. Thouverez and L. Jézéquel, 2004. Interaction of Squeeze Film Dampers and Hole Feed Systems and Its Influence on the Dynamics of a Jeffcott Rotor. International Journal of Rotating Machinery, vol. 10(3), pp. 163 - 174.

[5] P. Goldman, A. Muszynska, 1995. Rotor-to-Stator, Rub-related, Thermal/Mechanical Effects in Rotating Machinery. Chaos Solitons \& Fractals, vol 5, N9, pp. 1579-1601.

[6] Y. Maozhong, H. Baiyun, H. Jiawen, 2002. Erosion wear behaviour and model of abradable seal coating. Wear, vol. 252, pp. 9-15.

[7] H. Wang, 1996. Criteria for analysis of abradable coatings. Surface \& Coatings Technology, vol. 79, pp. 71-75.

[8] Z.C. Feng and Xiao-Zhang Zhang, 2002. Rubbing phenomena in rotor-stator contact. Chaos Solitons \& Fractals, vol. 14, pp. 257-267.

[9] S. Edwards, A. W. Lees and M. I. Friswell, 1999. The Influence of Torsion on Rotor/Stator Contact in Rotating Machinery. Journal of Sound and Vibration, vol. 225(4), pp. 767-778.

[10] G. von Groll and D. J. Ewins, 2001. The Harmonic Balance Method with arc-length Vol. 241(2), pp. 223-233. Systems. Journal of Applied Mechanics, vol. 48, pp. 929-935.

[11] S. H. Crandall and J. Dugundji, 1981. Resonant Whirling of Aircraft Propeller-Engine Systems. Journal of Applied Mechanics, vol. 48, pp. 929-935.

[12] G. Genta, 2003. On the stability of rotating blade array. Journal of Sound and Vibration, vol. 273, pp. 805-836.

[13] S. K. Sinha, 2004. Dynamic characteristics of a flexible bladed-rotor with Coulomb damping due to Tip-rub. Journal of Sound and Vibration, vol.273, pp. 875-919.

[14] B.O. Al-Bedoor and A. A. Al-Qaisia, 2004. Stability analysis of rotating blade bending vibration due to torsional excitation. Journal of Sound and Vibration, Article in press.

[15] Ö. Turhan and G. Bulut, 2003. Dynamic stability of rotating blades (beams) eccentrically clamped to a shaft with fluctuating speed. Journal of Sound and Vibration, Article in press. 